\title{
Uzaktan Algılama Yöntemleri İle Burdur Gölü'ndeki Alansal Değişiminin Belirlenmesi
}

\author{
Özümcan Alara Kaya1 ${ }^{1}$, Gordana Kaplan, ${ }^{2,}$
}

${ }^{1}$ Eskişehir Teknik Üniversitesi, Lisansüstü Eğitim Enstitüsü, Uzaktan Algılama ve CBS A.B.D., 25555, Eskişehir.

${ }^{2}$ Eskişehir Teknik Üniversitesi, Yer ve Uzay Bilimleri Enstitüsü, 25555, Eskişehir.

\section{Özet}

Sürdürülebilir su kaynakları yönetiminde kuraklığın izlenmesi, göller gibi su kütleleri için oldukça önemlidir. Su alanlarının haritalanması ve izlenmesi için uzaktan algılama yöntemleri ve teknikleri, son yıllarda başarll bir şekilde kullanılmaktadır. Bu çalıșmada Göller Yöresi bölgesinde, Isparta ile Burdur illeri arasında bulunan Burdur Gölü'nün 2009 ile 2019 yılları arasındaki alansal değişimi, uzaktan algılama teknikleri kullanılarak incelenmiştir. Çalışmada Landsat-7, Landsat-8 ve Sentinel-2 uydu görüntülerine obje bazlı sinıflandırma yapılmıștır. Sinıflandırmada, literatürde de sık kullanılan, normalleștirilmiș su fark indeksi (NDWI) kullanılmıştır. Çalıșmada kullanılan görüntüler Eylül ayını kapsamaktadır. Ek olarak mevsimsel değișim analizi için, 2017 ve 2019 yıllarının Nisan ve Mayıs aylarına ait Sentinel-2 uydu görüntüleri kullanılmıştır. Çalışma sonucunda elde edilen bulgulara göre; Burdur gölünün 2009-2019 yılları arasında 17 km² alan kaybettiğini göstermektedir. Landsat görüntüleri ile 2009-2019 yıllarına ait Eylül ayı verilerinin korelasyon analizi yapılmıștır ve analiz sonucu $R^{2}=0,94$ olarak elde edilmiştir. 2017 ve 2019 yıllarında, bahar ile sonbahar mevsimleri arasında, su alanında gözlenen azalma $2 \mathrm{~km}^{2}$ olarak belirlenmistir. Sinıflandırma doğrulukları \%90 - $\% 96$ arasında değişmektedir En yüksek sınıflama doğruluğu Sentinel-2 görüntüleri kullanılarak elde edilmiştir. Bu çalışma, su alanlarındaki alansal değişimlerin uzaktan algılama verileri ve teknikleriyle yüksek doğrulukta belirlenebileceğinin önemli bir örneğidir.

\section{Anahtar Sözcükler}

Alansal Değişim, Kuraklık, Uzaktan Algılama, Burdur Gölü

\section{Determination of Burdur Lake`s Area Changes Using Remote Sensing Techniques}

\begin{abstract}
Drought monitoring in water bodies such as lakes is essential for sustainable management of water resources. In recent years, remote sensing methods and techniques have been successfully used for mapping and monitoring water area changes. This study aimed to investigate the ten-year change between 2009 and 2019 in the Burdur Lake, located between Isparta and Burdur provinces in the Göller District, through remote sensing data and techniques. In the study, object-based classification was made using Landsat-7, Landsat-8, and Sentinel-2 satellite imagery. For the classification, the frequently used normalized water difference index (NDWI) combined with threshold analysis was used for water classification. All images were acquired in September. In addition to the seasonal variation analysis, Sentinel-2 images from April and May, 2017 and 2019 were used. As a result, in the last decade, Burdur lake has lost approximately $17 \mathrm{~km}^{2}$ of its water surface. Correlation analysis of the Landsat images of September for the years 2009-2019 resulted in an $R^{2}$ of 0,94. The change between spring and autumn in 2017 and 2019 was determined as $2 \mathrm{~km}^{2}$. The classification accuracies range from $90 \%$ to $96 \%$, and the highest classification accuracy was obtained with Sentinel-2 images. The results of the study show that the changes in water areas can be monitored with high accuracy through remote sensing data and techniques.
\end{abstract}

\section{$\underline{\text { Keywords }}$}

Area Changes, Drought, Remote Sensing, Burdur Lake

\section{Giriş}

Yaşam kaynağı olan su, ekolojik ve toplumsal aktivitelerin ayrılmaz bir parçasıdır. Yeryüzündeki değerli ve doğal kaynakların başında gelen su, dünyada ve Türkiye'de yoğun biçimde kullanılmaktadır. Özellikle yarı kurak iklime sahip, yıllık yağışın belirli mevsimlerde gerçekleştiği Türkiye gibi ülkelerde sürdürülebilir su kaynaklarının yönetimi, gün geçtikçe daha da önem kazanmaktadır. Sulak alanlar, yeryüzünün en zengin ve en üretken ekosistemlerini oluşturmaktadır. Bu alanlar, yöre insanları ile ülke geneline geniş yelpazede hizmet veren, oldukça karmaşık, doğal sistemlerdir ve yeryüzündeki başka hiçbir ekosistemle karşılaştırılamayacak ölçüde işlev ve değere sahiptir (Acharya vd. 2019; Aksoy vd. 2019; Anderson vd. 2018; Emanuel 2018; Giardino vd. 2010; Kaplan vd. 2019).

* Sorumlu Yazar: Tel: +90 (222) 3239129 Faks: +90 (222) 3222266

E-posta: ozumcanalarakaya@gmail.com (Kaya O.A), kaplangorde@gmail.com (Kaplan G)
Gönderim Tarihi / Received : 30/06/2020

Kabul Tarihi / Accepted 
Türkiye’nin yedinci büyük gölü olan Burdur Gölü, daha önce yapılan çalışmalardan da bilindiği üzere kurumaktadır (Sarp ve Ozcelik 2017; Yiğitbaşoğlu ve Uğur 2010). Bölgedeki iklimsel değişimler, artan antropojenik etkiler (havalimanı, yoğun olarak tarım amaçlı sulama suyu ile kullanımı, bölgede yapılan yapay göletler, barajlar ve endüstriyel amaçlı soğutma suyunda kullanma) sonucunda göl hem kurumaktadır hem de gölün su kalitesi düşmüştür. Daha önce yapılan araştırmalarda gölün su kalitesi ve göl alanındaki değişimler üzerine çalışılmıştır. Fakat gölün değişimi üzerine yapılan çalışmada, nesne tabanlı sınıflandırma ve mevsimsel değişimi uzaktan algılama yöntemi kullanılmamıştır.

Normalleștirilmiş su fark indeksi (Normalized Differance Water Index NDWI) analizi ile su sınırlarının belirlenmesi, son 20 yıldaki çalışmalarda kullanılmış olup bu çalışmalarda gayet başarılı sonuçlar elde edilmiştir (Yang vd. 2017), NDWI, Modife edilmiş normalleştirilmiş su fark indeksini (Modified NDWI, MNDWI) kullanarak su alanlarını belirlemiştir. Ek olarak SWIR bandı için pansharpenin yöntemini kullanmışlardır. Kaplan ve Avdan (2017), Sentinel-2 verilerini ve NDWI kullanarak Makedonya'da, nehir sınırları üzerine çalışmışlardır. Kwang vd. (2018), Landsat ve Sentinel verilerini ve NDWI kullanarak nehir sınırı çıkarımı yapıp iki uydu görüntüsünü de ayrıca karşılaştırmıştır.

Burdur Gölü günümüze dek birçok farklı çalışmaya konu olmuştur. Ataol (2010) gölün yıllık su kaybını yaklaşık 40 $\mathrm{hm}^{3}$ olarak hesaplamıştır. Öneri olarak ise mevcut yüzeysel sulama yöntemi yerine basınçlı sulamanın kullanılmasını sunmuş, bu yöntemin kullanılması hâlinde tasarruf edilecek su miktarını, gölün yıllık su kaybının bir buçuk katı olarak hesaplamıştır. Kaya vd. (2015) adlı çalışmada Türkiye'nin altıncı büyük göl havzası olan Burdur Gölü Havzası'nın ekolojisinin ve özellikle alanın endemik türü olan dikkuyruğun korunması amacıyla ulusal ve uluslararası literatür ve bölgeyle ilgili gözlemlerine dayanarak havzayı etkileyen etmenler ve havzayla ilgili sorunlarla ilgili olası çözüm önerileri üzerinde durmuştur. Temiz ve Durduran (2016), 1985-2015 y1lları arasında, gölün kıyı şeridindeki değişimleri Landsat uydusunun verilerini kullanarak hesaplamışlardır. Elde ettikleri verilere göre göl, 30 yılda $70 \mathrm{~km}^{2}$ ’lik küçülmüştür. Ek olarak Burdur Gölü için SWOT (Strengths, Weaknesses, Opportunities, Threats) analizi üzerinde de çalışma yapmışlardır.

Çalışmanın amacı; hem Burdur gölündeki değişimleri değerlendirmek hem de farklı uydu görüntülerin su sınıflandırmada değerlendirmek. Bu çalışmada Göller Yöresi bölgesinde, Isparta ile Burdur illeri arasında bulunan Burdur Gölü'nün on yıllık değişimi, uzaktan algılama teknikleri kullanılarak incelenmiştir. Çalışmada Landsat-7, Landsat-8, ve Sentinel-2 uydu görüntülerine obje bazlı sınıflandırma yapılmıştır. Sınıflandırmada, literatürde de sık kullanılan, NDWI kullanılmıştır. Tüm görüntüler eylül ayına aittir. Ek olarak mevsimsel değişim analizi için, 2017 ve 2019 yıllarının Nisan ve Mayıs aylarına ait Sentinel-2 uydu görüntüleri kullanılmıştır.

\section{Materyal ve Yöntem}

\section{1. Çalışma Alanı}

Burdur Gölü, göller yöresi bölgesinde Isparta ile Burdur illeri arasında yer almaktadır (Şekil 1). Göl, göller bölgesi’nin en büyük gölleri arasındadır. Kuşlar için önemli bir konaklama merkezi görevi gördüğü için Türkiye'nin 13 Ramsar alanından (uluslararası öneme sahip sulak alan) biri olarak tescillenmiş olup aynı zamanda Yaban Hayatı Geliştirme Sahası statüsüne sahiptir. Göl, küresel ölçekte nesli tehlike altında olan bir ördek türünün, dikkuyruğun (Oxyura leucocephala) yakın zamana kadar dünyadaki nüfusunun çok büyük bir kısmının kışladığı bir alan olup ayrıca gölde gölün tuzlu suyuna uyum sağlamış endemik balık türleri de bulunmaktadır (Ataol 2010).

Burdur Gölü, kuzeydoğu-güneybatı doğrultusunda Söğüt Dağı ile Sulu Dere, Yayla Dağları arasında yer alan çöküntü gölüdür. Gölün güney ve kuzeyinde bulunan alüvyon alanda sazlıklar mevcuttur. Göl, Burdur Kapalı Havzası'nda yer almaktadır kısacası havzadaki sular denize ulaşamamaktadır. Kapalı havzada yer almasına bağlı olarak gölün suyu tuzludur. Genel anlamda göl; yağışlardan, gölü besleyen yüzey ve yeraltı sularından beslenirken kapalı havza olma özelliğinden dolayı meydana gelen buharlaşma ve yer altındaki kaçaklar gölün başlıca su kayıp parametreleridir.

Akdeniz iklimi ile karasal iklim arasında bir geçiş zonunda yer alan Burdur Gölü, 30 y1l öncesine kadar fazla dalgalanma göstermeyen bir su seviyesine sahip iken 1987 yılından itibaren sürekli su kaybetmeye başlamıştır (Ataol 2010). 1971 yılında Burdur Gölü'nün en yüksek su seviyesine ulaşmış, 1971-2003 yılları arasında gölde su kaybı devam etmiş fakat 2003 yılında, su kaybında bir duraksama olmuştur (Yiğitbaşoğlu ve Uğur 2010).

2012 yılındaki Burdur Gölü’nün Sorunları, Çözümleri, Yönetimi ve Ekonomik Potansiyeli raporuna göre Burdur Gölü Havzası içerisinde 17 gölet, 1 rezervuar ve 1 baraj olmak üzere toplam 19 adet su tutma yapısı bulunmaktadır. Bu su tutma yapılarından 12 adet gölet, 1 adet rezervuar ve 1 adet baraj tali havzalarından biri olan Bozçay Havzası'nda, geriye kalan 5 adet gölet diğer tali havzalarda yer almaktadır.

Havzadaki meteoroloji istasyonlarının ölçümlerine göre, uzun yıllar bölgenin yağış ortalaması 447 mm'dir. 1995 'ten bu yana havzada yağışlı bir döneme girilmiş olmasına rağmen havzaya düşen yağışın neredeyse tamamı baraj ve göletlerde tutulduğu için, göl seviyesindeki düşüş, yağış artışına rağmen devam etmektedir. 


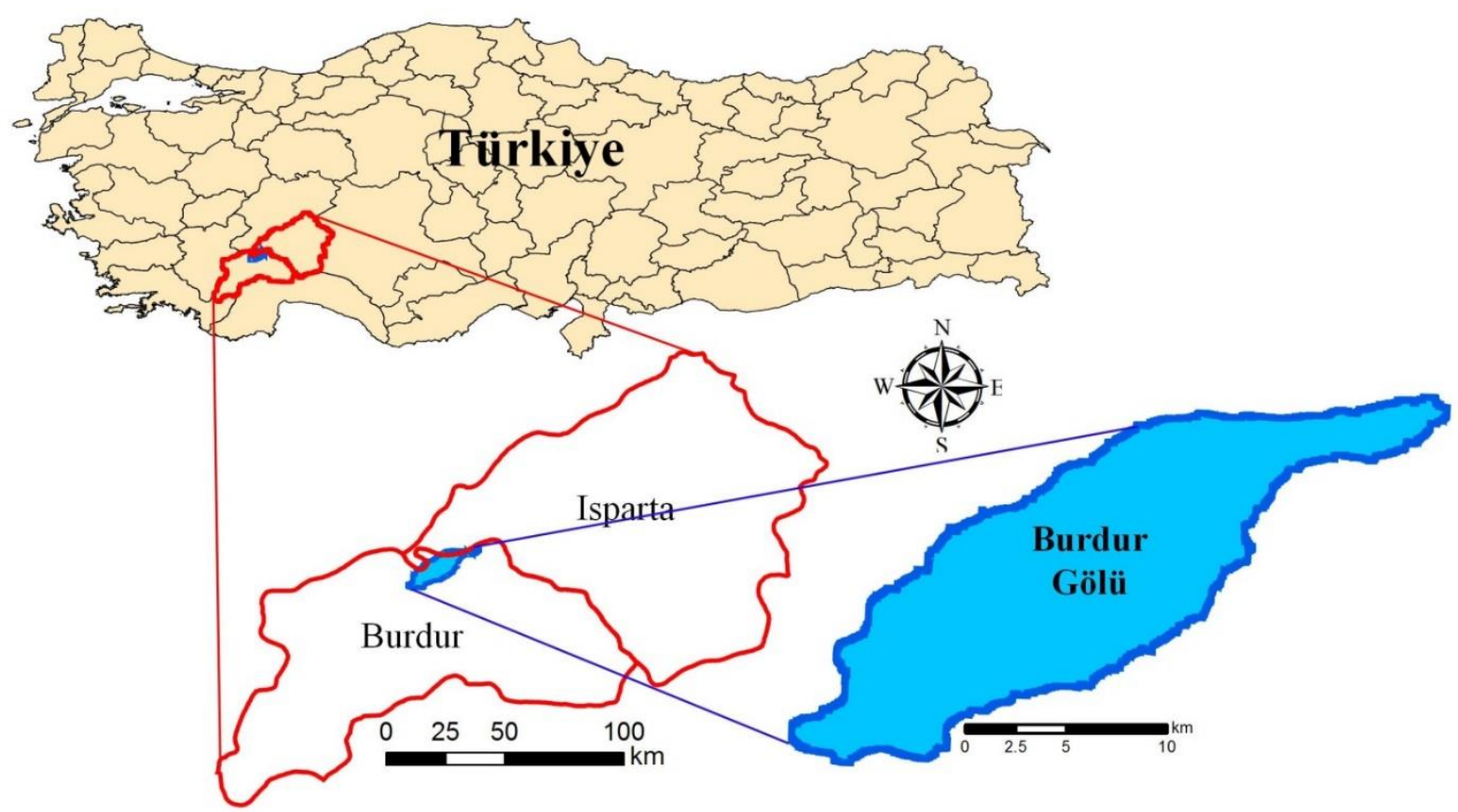

Şekil 1: Burdur gölü ve çevresine ait yerler ile ilgili harita

\subsection{Veri ve Yöntem}

Genel olarak Türkiye'deki yağışlar ile Türkiye'nin iklim özellikleri göz önünde bulundurulduğunda haziran-eylül ayları kurak dönemleri temsil ederken nisan-mayıs ayları ise yağışlı ayları temsil etmektedir. Çalışma alanında ilk olarak 20092019 yılları arasındaki kurak dönem (eylül ayı) değişimlerini belirlemek için https://earthexplorer.usgs.gov/ ve https://scihub.copernicus.eu/dhus sitelerinden Landsat ve Sentinel uydularına ait görüntüler indirilmiştir. Landsat-7, USGS ve NASA tarafından geliştirilen bir gözlem uydusudur. Uydu, Landsat Programı kapsamında geliştirilmiş olup uydunun ana hedefi, uydu fotoğraflarının küresel arşivini yenilemek, araştırmacılara güncel ve bulutsuz görüntüler sunmaktır. Program, USGS tarafından yönetilir, işletilir; Landsat-7'den gelen veriler, USGS tarafindan toplanır ve dağıtılır. Landsat-7, 15 Nisan 1999 tarihinde uzaya firlatılmıştır (URL-1 2020). Landsat-8; 11 Şubat 2013 tarihinde uzaya fırlatılan, USGS ve NASA tarafından geliştirilen bir gözlem uydusudur. Landsat 8 multispektral bantlarda $30 \mathrm{~m}$, pankromatik bantta ise $15 \mathrm{~m}$ mekansal çözünürlüklü veri toplamaktadır. Landsat 7'de mevcut olmayan pankromatik banda sahiptir.

Copernicus Programı'ndaki Avrupa Uzay Ajansı (AUA) tarafından geliştirilen Senitinel-2, Sentinel-2A ve Sentinel2B olmak üzere 2 uydudan oluşmaktadır. Bu uydular, $786 \mathrm{~km}$ yörünge yüksekliği ve 10, 20 ile $60 \mathrm{~m}$ konumsal çözünürlüğe sahip 13 adet spektral bandıyla kutupsal yörüngeli multi-spektral görüntü alabilmektedir. Sentinel-2A, 23 Haziran 2015 tarihinde ve Sentinel-2B 7 Mart 2017 tarihinde uzaya firlatılmıştır. İki uydu ekvatorda 5 günlük bir tekrar ziyaret süresi sağlamaktadır Sentinel-2 Uydusu, yüksek mekânsal çözünürlüklü olup günümüzde pek çok araştırmada kullanılmaktadır. Çalışma kapsamında kullanılan bantlar 10m konumsal çözünürlüğe sahiptirler. Tablo 1'de çalışma kapsamında kullanılan bantlara ait spektral özellikler verilmiştir. Landsat-7, Landsat-8 ve Sentinel-2 verilerinin özellikleri, Şekil 2'de (URL-2 2020) gösterilmiştir.

Kullanılan verilerde bulutluluk oranı \%10'dan küçüktür. Genel olarak bulutluluk durumu gölün çevresinde olup; bulutluluğun giderilmesi için ek bir düzeltme yapılmamıştır. Landsat uydu görüntüleri https://earthexplorer.usgs.gov/ internet sitesinden ön sipariş sonucu indirilmekle birlikte site, uydu görüntülerinde atmosferik ve radyometrik düzeltmeler yapmaktadır. Böylece Landsat verileri için atmosferik ve radyometrik düzeltmeler yapılmamıştır. Landsat-7'ye ait Satır Hatasını (Scan Line) düzeltmek için QGIS programı ve gap fill uygulaması kullanılmıştır. Şekil 3'de Landsat-7'ye ait olan görüntünün satır hatası düzeltilmeden önceki ve düzeltilmiş hali birlikte verilmiştir. Bu çalışmada kullanılan uydu görüntülerine ait özellikler Tablo 2'de verilmiştir. 
Tablo 1: Sentinel ve Landsat uydularını spektral özellikleri (URL-3 2020; URL-4 2020)

\begin{tabular}{|c|c|c|}
\hline \multicolumn{3}{|c|}{ Sentinel 2 Uydusunun Spektral Özellikleri } \\
\hline Bant Numarası & Spektral Çözünürlük (nm) & Konumsal Çözünürlük (m) \\
\hline Bant 2 Mavi & $458-523$ & 10 \\
\hline Bant 3 Yeşil & $543-578$ & 10 \\
\hline Bant 4 Kırmızı & $650-680$ & 10 \\
\hline Bant 8 Yakın Kızıötesi & $785-900$ & 10 \\
\hline
\end{tabular}

\begin{tabular}{|c|c|c|}
\hline \multicolumn{3}{|c|}{ Landsat 7 Uydusunun Spektral Özellikleri } \\
\hline Bant Numarası & Spektral Çözünürlük $(\boldsymbol{\mu m})$ & Konumsal Çözünürlük (m) \\
\hline Bant 1 Mavi & $0.441-0.514$ & 30 \\
\hline Bant 2 Yeşil & $0.519-0.601$ & 30 \\
\hline Bant 3 Kırmızı & $0.661-.-0.692$ & 30 \\
\hline Bant 4 Yakın Kızı̈ötesi & $0.772-0.898$ & 30 \\
\hline
\end{tabular}

\begin{tabular}{|c|c|c|}
\hline \multicolumn{3}{|c|}{ Landsat 8 Uydusunun Spektral Ö̈zellikleri } \\
\hline Bant Numarası & Spektral Çözünürlük $(\boldsymbol{\mu m})$ & Konumsal Çözünürlük (m) \\
\hline Bant 2 Mavi & $0.452-0.512$ & 30 \\
\hline Bant 3 Yeşil & $0.533-0.590$ & 30 \\
\hline Bant 4 Kırmızı & $0.636-0.673$ & 30 \\
\hline Bant 5 Yakın Kızı̈lötesi & $0.851-0.879$ & 30 \\
\hline
\end{tabular}

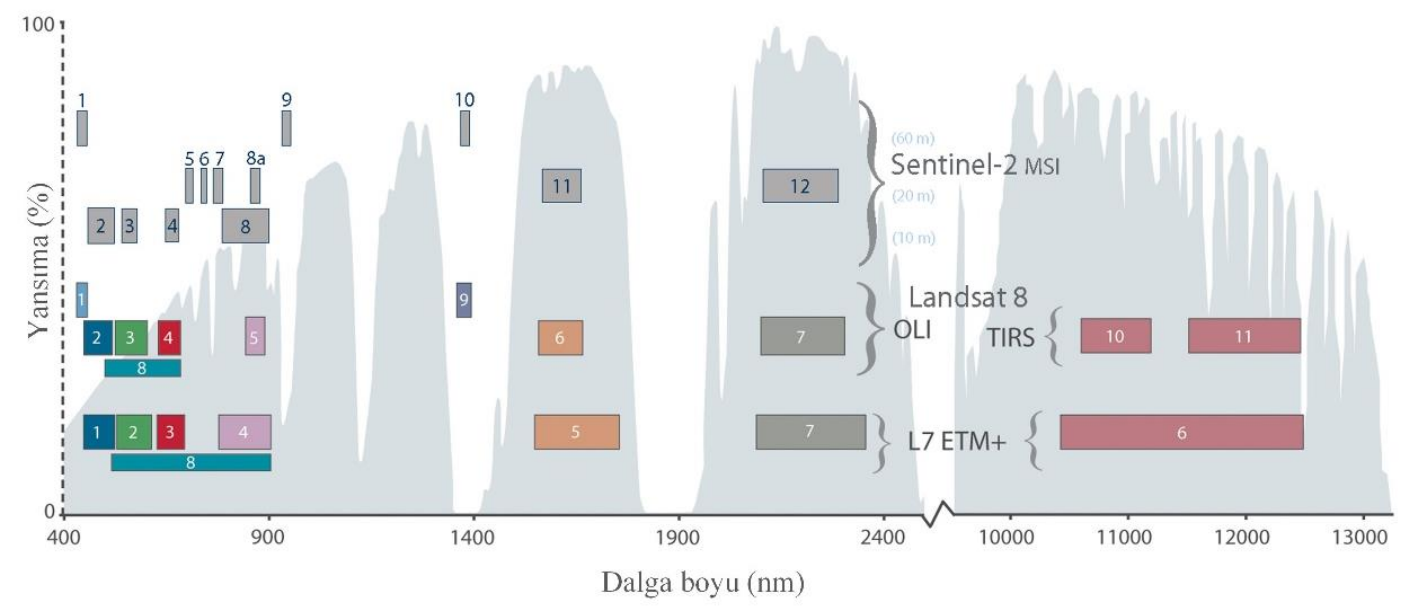

Şekil 2: Landsat-7 ile 8 ve Sentinel-2 bantlarının karşılaştırılması (URL-2 2020)

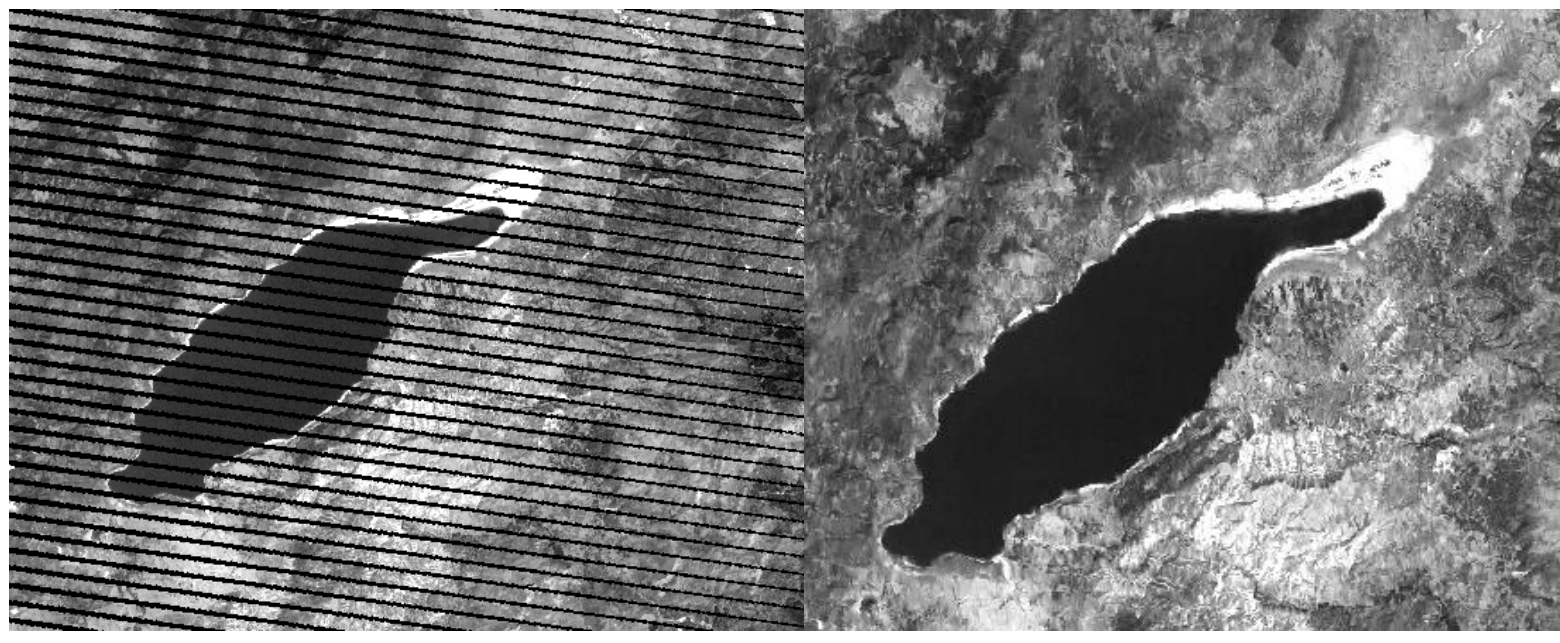

Şekil 3: Satır hatası düzeltilmeden önceki hali (solda), satır hatası düzeltilmiş hali (sağda) verilmiştir 
Tablo 1: Uydu görüntülerine ait özellikler

\begin{tabular}{lllll}
\hline Yll & Görüntü Tarihi & Uydu & Uydu Özelliği & İndirilen Site \\
\hline $\mathbf{2 0 0 9}$ & $06 / 09 / 2009$ & Landsat & Landsat 7_TM & Earth Explorer \\
$\mathbf{2 0 1 1}$ & $05 / 09 / 2011$ & Landsat & Landsat 7_TM & Earth Explorer \\
$\mathbf{2 0 1 3}$ & $09 / 09 / 2013$ & Landsat & Landsat 8_TM & Earth Explorer \\
$\mathbf{2 0 1 5}$ & $08 / 09 / 2015$ & Landsat & Landsat 8_TM & Earth Explorer \\
& $18 / 09 / 2015$ & Sentinel & Sentinel 2_2A & Copernicus \\
$\mathbf{2 0 1 7}$ & $20 / 09 / 2017$ & Landsat & Landsat 8_TM & Earth Explorer \\
& $07 / 09 / 2017$ & Sentinel & Sentinel 2_2A & Copernicus \\
$\mathbf{2 0 1 9}$ & $10 / 09 / 2019$ & Landsat & Landsat 8_TM & Earth Explorer \\
& $07 / 09 / 2019$ & Sentinel & Sentinel 2_2A & Copernicus \\
\hline
\end{tabular}

Pankeskinleştirme; uydu görüntülerinde bulunan düşük çözünürlüğe sahip renkli bantların yüksek çözünürlüklü pan bandı kullanılarak çözünürlüğünün arttırılmasını sağlayan veri bütünleştirme (fusion) yöntemleridir (URL-5 2020). Çalışmada Landsat-7 ve Landsat-8 uydusu için görüntü keskinleştirme uygulanmıştır. Bu kapsamda Envi Programı ile Gram Schmidt Metodu kullanılmıştır.

Literatürde birçok çalışmalarda NDWI su alanlarını sınıflandırmak için kullanılmıştı, fakat son yıllarda yapılan çalışmalarda nesne bazlı sınıflandırma ve NDWI kullanarak daha yüksek doğruluk elde edildiğini ortaya çıkmıştır (Kaplan ve Avdan 2017). Burdur Gölü'nün sınırlarını çıkarmak için nesne bazlı sınıflandırma yapılmıştır. Sınıflandırma yöntemi olarak NDWI değerlerine eşik tanımlanmıştır ve sıfırdan büyük NDWI değere sahip olan objeler, su sınıfına atanmıştır. Analizler için eCognition Programı kullanılmıştır. Nesne bazlı sınıflandırmanın ilk adımı, segmentasyon işlemidir. Çalışmada Çoklu Çözünürlüklü Segmentasyon yöntemi uygulanmıştır. Çalışmanın amacı, Burdur Gölü’nün sınırlarını belirlemek olduğu için çalışmada iki sınıf mevcuttur: su ve diğer alanlar. Çoklu çözünürlüklü segmentasyonda sulak alanı daha iyi belirlemek amacıyla yakın kızıl ötesi bandına, kırmızı, mavi ve yeşil banttan daha fazla ağırlık verilmiştir. Farklı parametreler deneyip Burdur Gölü'nün sınırlarını çıkarmak için en uygun değerler seçilmiştir. Bu çalışmada segmentasyon sırasında kullanılan parametreler Tablo 3'te verilmiştir, Şekil 4'te eCognition programı kullanılarak elde edilen Sentinel 2 uydusunun 2019 yılının eylül ayına ait segmantasyon figürü yer almaktadır. Segmentasyondan sonra NDWI değerleri kullanılıp sınıflandırma yapılmıştır. Burdur Gölünün sınırlarını çıkarmak için sıfırdan büyük değerler su sınıfına atanmıştır. NDWI'ın formülü aşağıda verilmiştir.

$N D W I=\frac{Y e s ̧ i l-Y K O ̈}{Y e s ̧ i l+Y K O ̈}$

NWDI değerleri hesaplamak için Landsat-7'nin ikinci ve dördüncü, Landsat-8'in üçüncü ve beşinci ve Sentinel-2'nin üçüncü ve sekizinci bantları kullanılmıştır.

Sonuçların doğruluğunu hesaplamak için çalışma alanının üzerinde, rastgele nokta yöntemi ile doğruluk analizleri yapılmıştır. Çalışma kapsamında 2 sınıf sulak alan ve diğer alanlar yer aldığından her sınıfa 100'er adet olmak üzere toplamda 200 örnek noktası atılmıştır. Landsat verileri ile Sentinel eylül ayı verilerine doğruluk analizi yapılmıştır.

Tablo 3: Segmentasyon parametreleri

\begin{tabular}{cc}
\hline & Mavi: 1 \\
Bant ağırlıklar & Yeşil: 1 \\
& Kırmızı: 1 \\
& Yakın kızıl ötesi: 2 \\
\hline Ölçek parametresi & 100 \\
Biçim parametresi & 0.8 \\
Yoğunluk parametresi & 0.3 \\
\hline
\end{tabular}




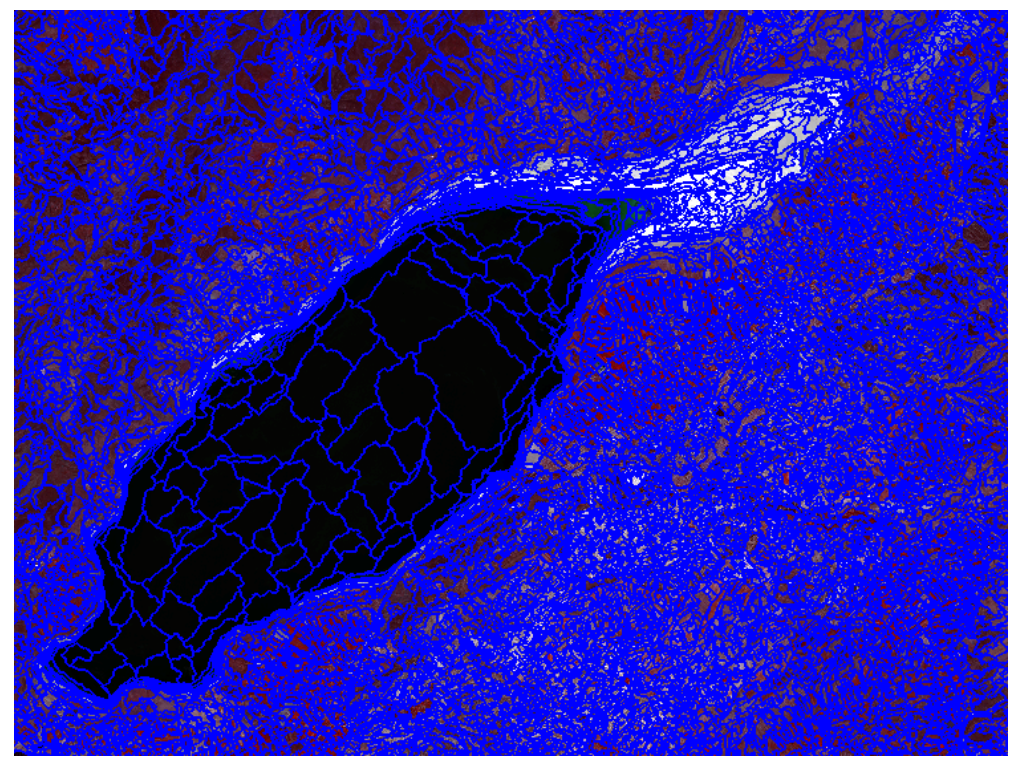

Şekil 4: Sentinel 2 uydusunun 2019 Eylül ayına ait görüntüsünün segmantasyon işlemi

\section{Bulgular}

Bu çalışmada Göller Yöresi bölgesinde, Isparta ile Burdur illeri arasında bulunan Burdur Gölü'nün on y1llık değişimi uzaktan algılama teknikleri kullanılarak incelenmiştir. Çalışma, farklı mekânsal çözünürlüklere sahip iki uydunun verileri ile elde edilen bulguları da karşılaştırma imkanı sağlamıştır.

Daha iyi sonuç alabilmek için, görüntü keskinleştirme yöntemiyle Landsat verilerinin çözünürlüğü 15 m'ye çıkarılmıştır. Görüntülerin detayları incelendiğinde kalitesinin arttı̆̆ı görülmüştür. Böylece nesne tabanlı sınıflandırmaları, 15 m Landsat ve 10 m Sentinel-2'nin görüntüleri üzerinde yapılmıştır.

\subsection{Analiz Bulguları}

Çalışma kapsamında ilk olarak Landsat-7 ve 8 uydularına ait 2009, 2011, 2013, 2015, 2017, 2019 yıllarında, eylül ayında çekilmiş veriler değerlendirilmiştir. Daha sonra da daha yüksek çözünürlüğe sahip $(10 \mathrm{~m})$ Sentinel Uydusuna ait 2015, 2017, 2019 yıllarının eylül ayı görüntüleri kullanılmıştır. Son olarak mevsimsel değişim analizi için Sentinel Uydusuna ait 2017 ile 2019 yıllarının Nisan ve Mayıs ayı görüntülerinden Burdur Gölü alan değişimi incelenmiştir.

\subsubsection{Landsat Bulguları}

Lansdsat-7 görüntüleri ile 2009 ve 2011 yıllarının Eylül verileri, Landsat-8 görüntüleri ile de 2013 yılının Eylül ayı verisi elde edilmiştir. Daha önceden de bahsedildiği üzere görüntülerin çözünürlükleri görüntü keskinleştirme yöntemiyle $15 \mathrm{~m}$ yükseltilmiştir.

Sonuçlar Tablo 4'te verilmiştir. 2009'da gölün alanı $142 \mathrm{~km}^{2}$, 2011'de $139 \mathrm{~km}^{2}$ ve 2013 'te $136 \mathrm{~km}^{2}$ olarak hesaplanmıştır (Tablo 4 ve Şekil 5). 2009-2013 yılları arasındaki yıllık değişim $1.5 \mathrm{~km}^{2}$ 'dir.

Tablo 4: 2009-2013 yıllarına ait alan verisi

\begin{tabular}{cc}
\hline Yıllar & Alan $\left(\mathbf{k m}^{\mathbf{2}}\right)$ \\
\hline $\mathbf{2 0 0 9}$ & 142 \\
$\mathbf{2 0 1 1}$ & 139 \\
$\mathbf{2 0 1 3}$ & 136 \\
\hline
\end{tabular}




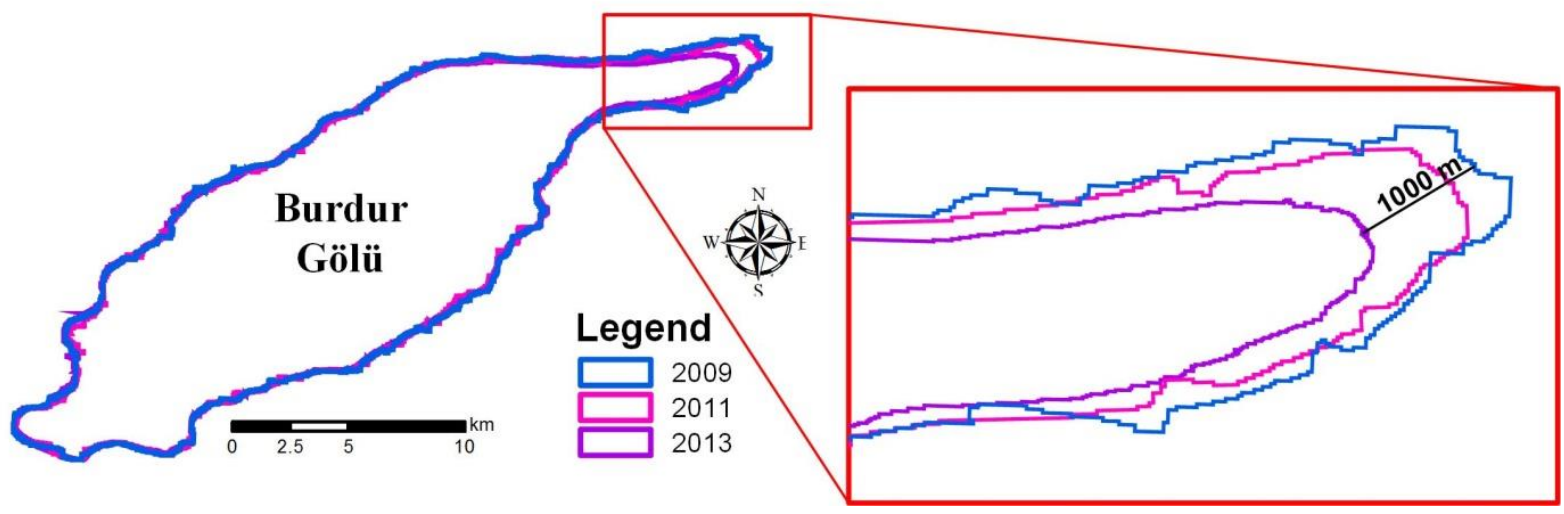

Şekil 5: Landsat - 7; 2009-2013 Eylül ayında gölün alansal değişimi

Landsat -8 görüntüleriyle 2019 ile 2017 yıllarının ve 2015 yılının Eylül ayı verileri elde edilmiştir. Gölün alanı, 2015 'te $136 \mathrm{~km}^{2}, 2017$ 'de $130 \mathrm{~km}^{2}, 2019$ 'da da $126 \mathrm{~km}^{2}$ olarak hesaplanmıştır. 2015-2019 yıllarının arasındaki değişim, 10 $\mathrm{km}^{2}$ 'dir. Sonuçlar Tablo 4 ve Şekil 6'da verilmiştir.

Tablo 2: 2015-2019 yıllarına göre göl alanları

\begin{tabular}{cc}
\hline Yillar & Alan $\left(\mathbf{k m}^{\mathbf{2}}\right)$ \\
\hline $\mathbf{2 0 1 5}$ & 136 \\
$\mathbf{2 0 1 7}$ & 130 \\
$\mathbf{2 0 1 9}$ & 126 \\
\hline
\end{tabular}

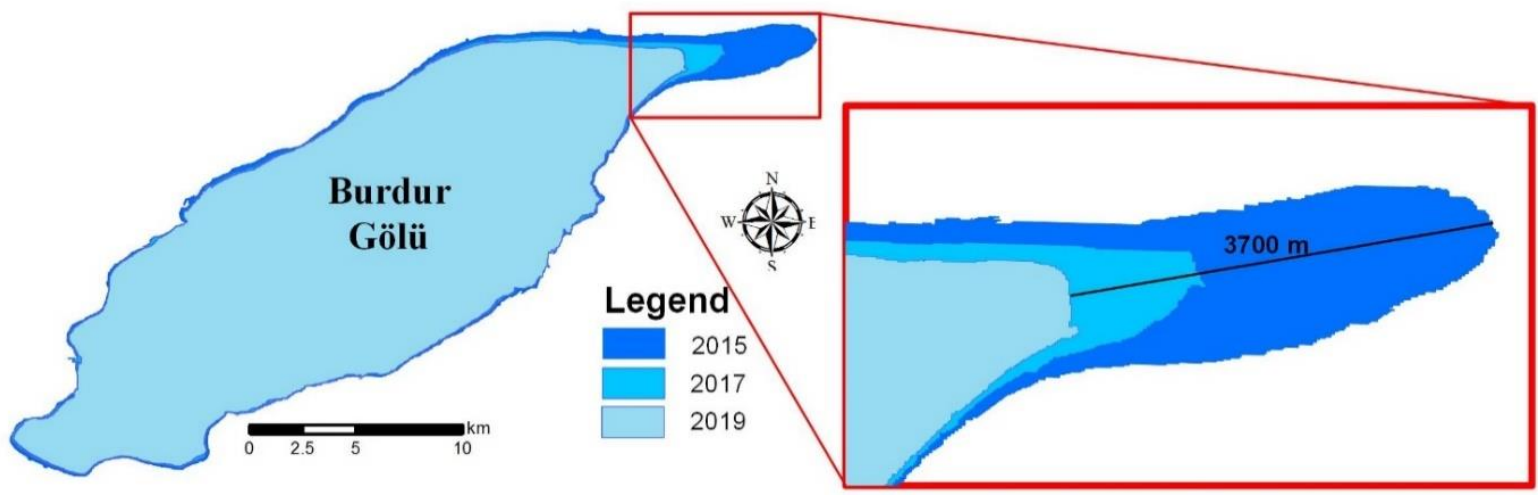

Şekil 6: Landsat - 8; 2015-2019 Eylül ayında gölün alansal değişimi.

\subsubsection{Sentinel Bulguları}

Sentinel-2 görüntüleri sonucunda elde edilen verilere göre, 2015-2019 yılları arasında su alanı $10 \mathrm{~km}^{2}$ azalmıştır. Sonuçlar Tablo 5 ve Şekil 7'de gösterilmiştir.

Tablo 3: 2015-2019 yıllarına göre göl alanları

\begin{tabular}{cc}
\hline Yıllar & Alan $\left(\mathbf{k m}^{\mathbf{2}}\right)$ \\
\hline $\mathbf{2 0 1 5}$ & 135 \\
$\mathbf{2 0 1 7}$ & 129 \\
$\mathbf{2 0 1 9}$ & 125 \\
\hline
\end{tabular}




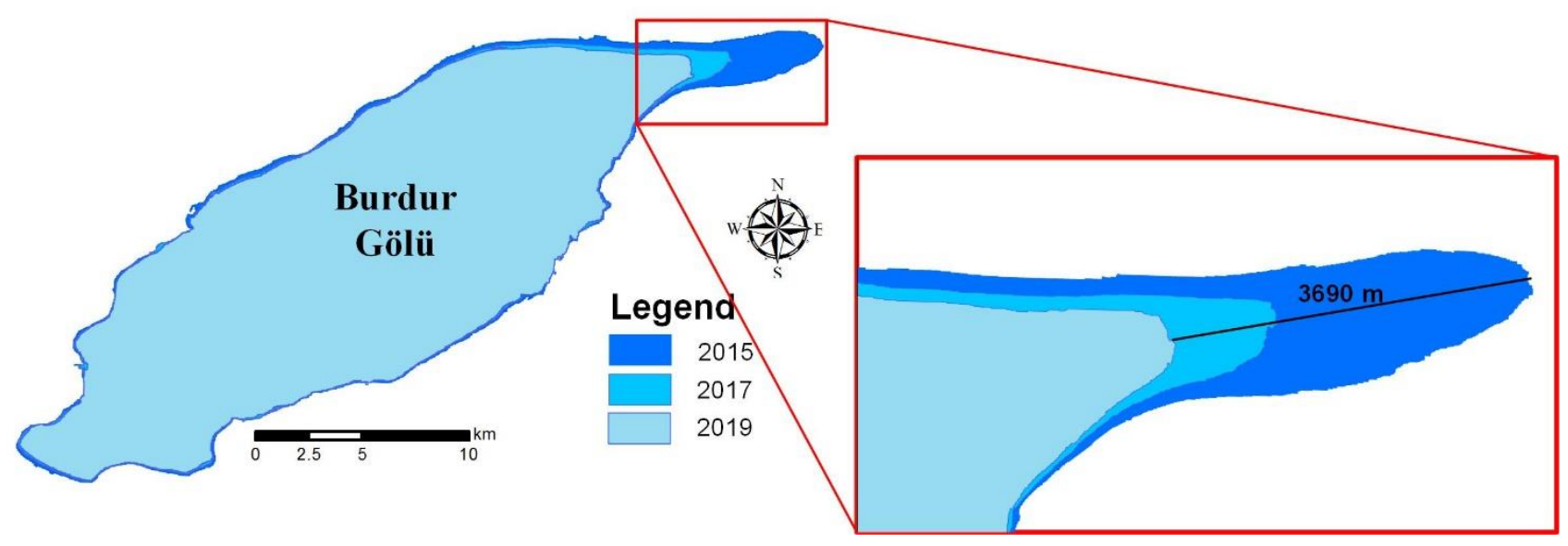

Şekil 7: Sentinel - 2 2015-2019 yılları Eylül ayında gölün alansal değişimi

\subsubsection{Genel Değerlendirme}

2009-2019 yılları arasındaki Landsat eylül ayı verileri toplu olarak değerlendirilmiştir (Şekil 8). Göl, toplamda 16 km² 'lik bir azalış göstermiştir. Fakat bu azalış, düzenli bir şekilde olmamıştır. 2009-2013 yılları arasında yıllık ortalama 1.5 km²'lik bir azalış söz konusuyken 2013 ile 2015 yıllarında bir azalış görülmemektedir. Buna karşın 2015-2017 yılları arasında $6 \mathrm{~km}^{2}$ 'lik bir azalış görülmüştür. 2017-2019 yıllarında, yine ortalama $1.5 \mathrm{~km}^{2}$ ’lik bir azalış söz konusudur. Şekil 9'da alansal değişimin yıllara bağılı korelasyonu gösterilmiştir. Korelasyon, su miktarındaki yıllık değişimin doğrusal olarak azaldığını göstermektedir.

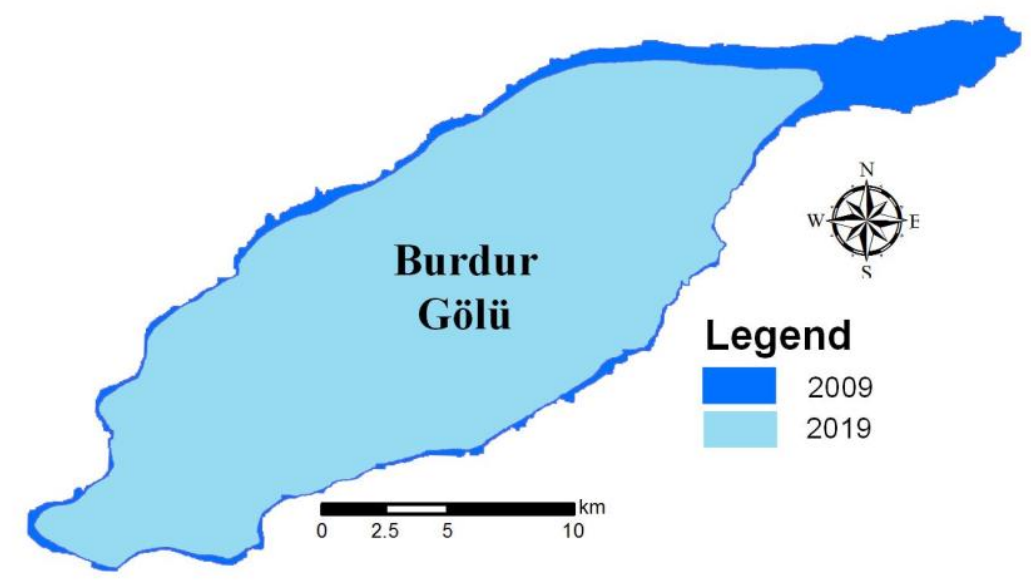

Şekil 8: 2009-2019 Eylül ayı gölün alansal değişimi

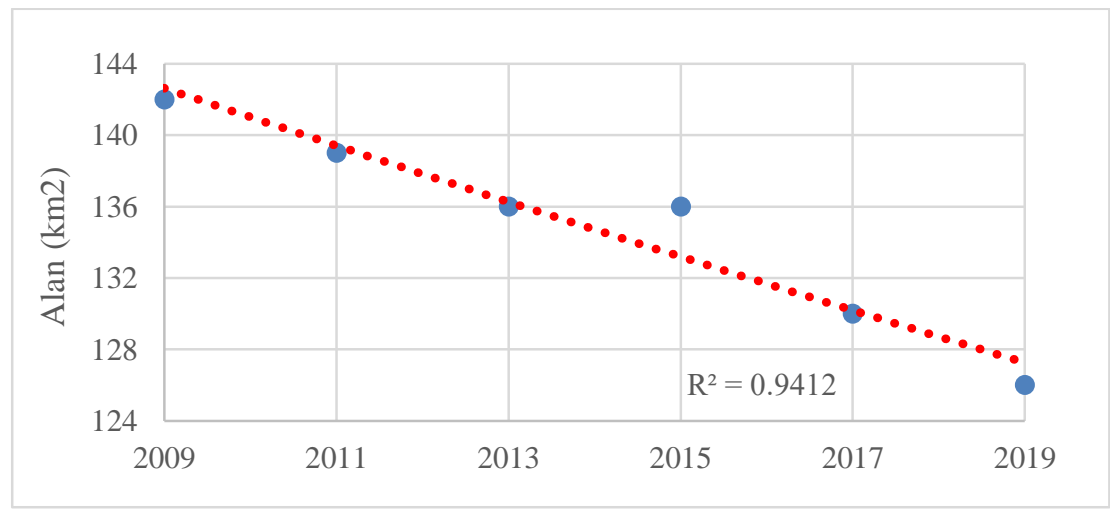

Şekil 9: Alansal değişimin korelasyonu 


\subsubsection{Mevsimsel Değişim}

10 m çözünürlüğe sahip Sentinel-2 uydu görüntüleri kullanılarak 2017 ve 2019 yılları için, mevsimsel ve kurak dönemlerdeki farklar üzerine çalışılmıştır. Her iki yılda da bahar (nisan-mayıs) ve sonbahar (eylül) mevsimlerinin arasındaki değişim, 2 km² olarak tespit edilmiştir. Sonuçlar Tablo 6 ve Şekil 10'de verilmiştir.

Tablo 4: 2017-2019 yıllarına göre mevsimsel değişim

\begin{tabular}{ccc}
\hline Yllar & Bahar $\left(\mathbf{k m}^{\mathbf{2}}\right)$ & Sonbahar $\left(\mathbf{k m}^{\mathbf{2}}\right)$ \\
\hline $\mathbf{2 0 1 9}$ & 127 & 125 \\
$\mathbf{2 0 1 7}$ & 131 & 129 \\
\hline
\end{tabular}

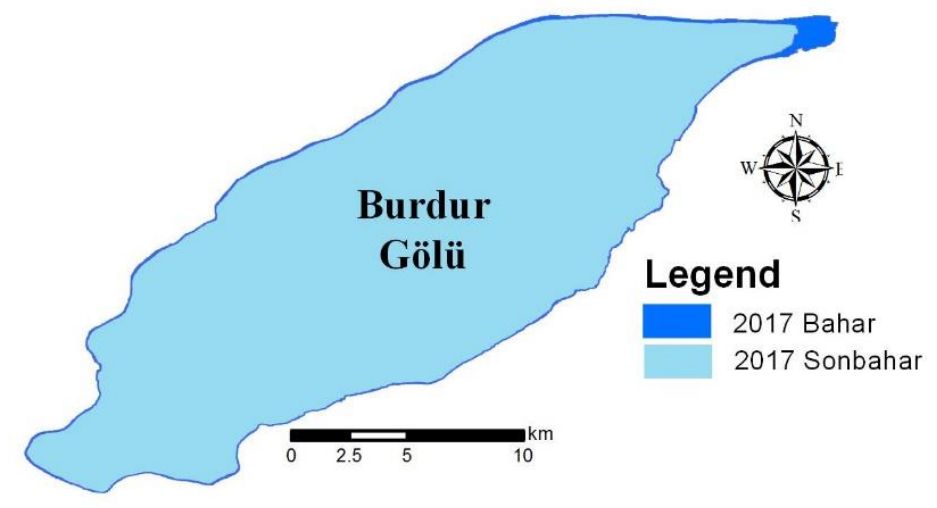

Şekil 10: 2017 yılı Burdur Gölü'nün mevsimsel alansal değişimi

\subsection{Doğruluk Analizi}

Çalışma kapsamında 2 sınıf sulak alan ve diğerleri mevcut olduğundan her sınıfa 100'er adet olmak üzere toplamda 200 örnek noktası atılmıştır (Banko 1998). Noktalar çalışma alanı üzerinde rastgele bir şekilde dağıtılmıştır (Şekil 11). Doğruluk analizi, Landsat verileri ve Sentinel Eylül ayı verilerine göre yapılmıştır.

2009-2019 yıllarının Eylül ayı verileri için doğruluk analizleri yapılmıştır. En düşük doğruluk, 2011 yılına ait olup \%89'dur. En yüksek doğruluk sonucu ise 2019 yılına ait olup \%95'dir. Doğruluk analizlerinin sonuçları Tablo 7'de verilmiştir.

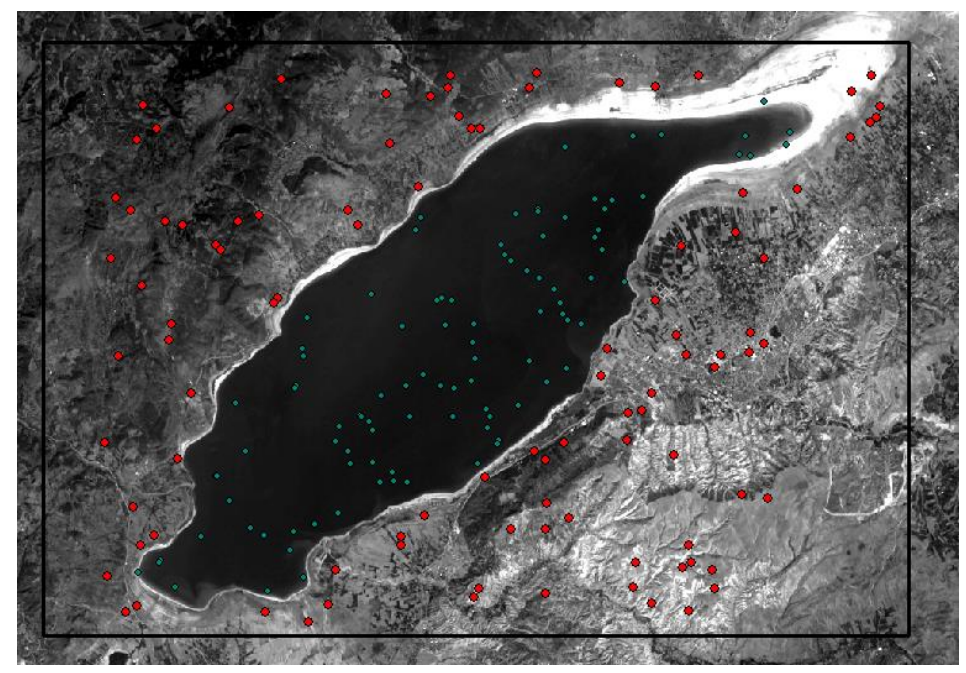

Şekil 11: Doğruluk Analizi için çalışma alanına ait rastgele seçilen noktalar 
Tablo 7: Landsat doğruluk analizi matrisleri

\begin{tabular}{|c|c|c|c|c|c|c|c|c|c|}
\hline & & $\begin{array}{l}\text { andsat } \\
\text { Refer }\end{array}$ & & & & & $\begin{array}{l}\text { sat }-8 \\
\text { ferans }\end{array}$ & & \\
\hline & $\mathrm{Su}$ & Diğer & Toplam & & & $\mathrm{Su}$ & Diğger & Toplam & \\
\hline $\mathrm{Su}$ & 89 & 11 & 100 & 0.89 & $\mathrm{Su}$ & 95 & 5 & 100 & 0.95 \\
\hline Diğger & 10 & 90 & 100 & 0.90 & Diğger & 12 & 88 & 100 & 0.88 \\
\hline Toplam & 99 & 101 & 200 & & Toplam & 107 & 93 & 200 & \\
\hline & 0.90 & 0.89 & & 0.90 & & 0.89 & 0.95 & & 0.92 \\
\hline & & $\begin{array}{l}\text { sat }-7 \\
\text { ferans }\end{array}$ & & & & & $\begin{array}{l}\text { sat }-8 \\
\text { ferans }\end{array}$ & & \\
\hline & $\mathrm{Su}$ & Diğger & Toplam & & & $\mathrm{Su}$ & Diğer & Toplam & \\
\hline $\mathrm{Su}$ & 86 & 14 & 100 & 0.86 & $\mathrm{Su}$ & 93 & 7 & 100 & 0.93 \\
\hline Diğger & 9 & 91 & 100 & 0.91 & Diğer & 9 & 91 & 100 & 0.91 \\
\hline Toplam & 95 & 105 & 200 & & Toplam & 102 & 98 & 200 & \\
\hline & 0.91 & 0.87 & & 0.89 & & 0.91 & 0.93 & & 0.92 \\
\hline & & $\begin{array}{l}\text { sat }-7 \\
\text { ferans }\end{array}$ & & & & & $\begin{array}{l}\text { sat - 8 } \\
\text { ferans }\end{array}$ & & \\
\hline & $\mathrm{Su}$ & Diğger & Toplam & & & $\mathrm{Su}$ & Diğer & Toplam & \\
\hline $\mathrm{Su}$ & 94 & 6 & 100 & 0.94 & $\mathrm{Su}$ & 97 & 3 & 100 & 0.97 \\
\hline Diğger & 10 & 90 & 100 & 0.90 & Diğger & 6 & 94 & 100 & 0.94 \\
\hline Toplam & 104 & 96 & 200 & & Toplam & 103 & 97 & 200 & \\
\hline & 0.90 & 0.94 & & 0.92 & & 0.94 & 0.97 & & 0.96 \\
\hline
\end{tabular}

2015 - 2019 yılları Sentinel-2 görüntülerinden, eylül ayı verileri için doğruluk analizi yapılmıştır. En düşük doğruluk, 2015 yılına ait olup \%94'tür. En yüksek doğruluk sonucu ise 2019 yılına ait olup \%96'dir. Her iki uydu görüntüsü karşılaştırıldığında Sentinel-2 Uydusuna ait görüntülerin daha yüksek doğruluk değerlerine sahip olduğu görülmüştür. Bunun nedeni de Sentinel-2 uydusunun 10 m mekânsal çözünürlüğe sahip olmasıdır. Buna karşılık çalışma kapsamında Landsat uydu görüntülerinin de görüntü keskinleştirme metoduyla mekânsal çözünürlükleri 15 m yükseltilmiştir. Tablo 8'de Sentinel-2 uydu görüntülerinden yapılan sınıflandırmanın doğruluk analizi verilmiştir.

Tablo 8: Sentinel-2 doğruluk analizi matrisleri

\begin{tabular}{|c|c|c|c|c|}
\hline \multicolumn{5}{|c|}{$\begin{array}{c}\text { Sentinel - } 2 \text { / } 2015 \\
\text { Referans veri }\end{array}$} \\
\hline & $\mathrm{Su}$ & Diğer & Toplam & \\
\hline $\mathrm{Su}$ & 95 & 5 & 100 & 0.95 \\
\hline Diğer & 6 & 94 & 100 & 0.94 \\
\hline Toplam & 101 & 99 & 200 & \\
\hline & 0.94 & 0.95 & & 0.95 \\
\hline \multicolumn{5}{|c|}{ Sentinel - 2 / 2017} \\
\hline & $\mathrm{Su}$ & Diğer & Toplam & \\
\hline $\mathrm{Su}$ & 93 & 7 & 100 & 0.93 \\
\hline Diğer & 3 & 97 & 100 & 0.97 \\
\hline Toplam & 96 & 104 & 200 & \\
\hline & 0.97 & 0.93 & & 0.95 \\
\hline \multicolumn{5}{|c|}{ Sentinel -2 / 2019} \\
\hline & $\mathrm{Su}$ & Diğer & Toplam & \\
\hline $\mathrm{Su}$ & 95 & 5 & 100 & 0.95 \\
\hline Diğer & 4 & 96 & 100 & 0.96 \\
\hline Toplam & 99 & 101 & 200 & \\
\hline & 0.96 & 0.95 & & 0.96 \\
\hline
\end{tabular}




\section{Sonuçlar ve Tartışma}

$\mathrm{Bu}$ çalışmada; hem Burdur gölündeki değişimleri değerlendirip hem de farklı uydu görüntülerin su sınıflandırmada değerlendirilmiştir. Çalışmada Göller Yöresi bölgesinde, Isparta ile Burdur illeri arasında bulunan Burdur Gölü'nün on yıllık değişimi, uzaktan algılama teknikleri kullanılarak incelenmiştir. Çalışmada Landsat-7, Landsat-8 ve Sentinel-2 uydu görüntülerine obje bazlı sınıflandırma yapılmıştır. Sınıflandırmada, literatürde de sık kullanılan, NDWI kullanılmıştır. Kullanılan görüntüler eylül ayına aittir. Ek olarak mevsimsel değişim analizi için 2017 ve 2019 yıllarının Nisan ve Mayıs aylarına ait Landsat uydusundan daha yüksek mekânsal çözünürlüğe sahip Sentinel-2 uydu görüntüleri kullanılmıştır.

Daha önce birçok çalışmada kullanılan NDWI analiz ve obje bazlı kontrollü sınıflama, Burdur Gölü için de yapıllmıştır. Elde edilen sonuçlara göre göl, 2009-2019 yılları arasında alansal olarak küçülmeye devam etmiştir. Göl, 2009-2013 yılları arasında yıllık $1.5 \mathrm{~km}^{2}$ küçülürken 2015-2019 yılları arasında ortalama yıllık 3 km² küçülmüştür. Mevsimsel olarak incelendiğinde ise ortalama $2 \mathrm{~km}^{2}$ 'lik bir değişim söz konusudur.

Farklı mekansal çözünürlüklere sahip iki uydu için doğruluk analizi sonuçları farklılık göstermektedir. Landsat uydu görüntülerinde doğruluk analizi sonuçları \% 89-95 arasında değişmektedir. Sentinel uydu görüntülerinde doğruluk analizi sonuçları \% 94-96 arasında değişmektedir. Genel olarak doğruluk analizi \%90 ve üzerinde olup; Landsat uydu görüntüleri için uygulanan pankeskinleştirme sonucu artan mekânsal çözünürlük doğruluk değerlerini de arttırmıştır. Mekansal çözünürlük arttıkça doğruluk değerleri de artmaktadır.

2012 yılına ait Burdur Gölü raporu verilerine göre 1970 yılında gölün alanı 274 km² iken 2012 yılında 149 km² olarak hesaplanmıştır. Göl, 42 yılda 125 km² küçülmüştür. 42 yıl için yıllık değişim miktarı ise 2.9 km²' dir. Temiz vd. (2017)'ye göre göl, 1985-2015 yılları arasında 70 km² küçülmüştür. Yıllık değişim miktarı ise 2,3 km²' dir. Gölün alanı ise son 10 yılda yıllık ortalama 1,6 km² azalmıştır. Daha önce elde edilen veriler ve elde ettiğimiz veriler birlikte incelendiğinde, gölün azalım trendinin değişim gösterdiği görülmektedir. Genel trendde yıllık değişim $2.5 \mathrm{~km}^{2}$ alınırsa ve bu trend devam ederse gölü besleyen parametrelerde bir artış, değişim söz konusu olmaz ise genel anlamda 2070 y1lında göl tamamen kuruyabilir. Gölün su seviyesindeki farklılığın sadece mevsimsel değişimler sonucu olmadığı açıktır. Daha önceki çalışmalarda da belirtildiği üzere gölü besleyen suların akışının değiştirilmesi artan antropojenik etkilerden de kaynaklanmaktadır. Göl alanının azalması fakat buharlaşmanın sabit olması dolayısıyla da gölün su kalitesinin düşeceği (artan tuzluluk oranı) bilinmektedir.

Daha sonraki çalışmalarda bölgedeki tarım alanları nesne tabanlı sınıflama ile belirlenip bu alanlardaki tarım ürünlerinin su ihtiyacı saptandığında mevsimsel bazlı değişimin nedeni ortaya konulabilir. Bunlara ek olarak gölü besleyen akarsuların hidrolojik özellikleri UA ve CBS yöntemleri ile belirlenerek göl için detaylı bir modelleme yapılabilir.

\section{Teşekkür}

Bu çalışma, Eskişehir Teknik Üniversitesi'nde yürütülen Uzaktan Algılamada Özel Konular dersi kapsamında yapılmıştır. Değerli yorumları ve katkıları için Majid Aghlmand ve Mohammad Asef Mobariz’e teşekkürlerimizi sunarız.

\section{Kaynaklar}

Acharya T.D., Subedi A., Lee D.H., (2019), Evaluation of machine learning algorithms for surface water extraction in a Landsat 8 scene of Nepal, Sensors, 19(12), 2769, doi: 10.3390/s19122769.

Aksoy T., Sarı S., Çabuk A.,(2019), Sulak alanların yönetimi kapsamında su indeksinin uzaktan algılama ile tespiti, Göller Yöresi, GSI Journals Serie B: Advancements in Business and Economics, 2(1), 35-48.

Anderson M., Gao F., Knipper K., Hain C., Dulaney W., Baldocchi D., Eichelmann E., Hemes K., Yang Y., Medellin-Azuara J., (2018), Field-scale assessment of land and water use change over the California Delta using remote sensing, Remote Sensing, 10(6), 889, doi: 10.3390/rs10060889.

Ataol M., (2010), Burdur Gölü'nde seviye değişimleri (The water level changings in Burdur Lake), Turkish Journal of Geographical Sciences, 8(1), 77-92.

Banko G., (1998), A review of assessing the accuracy of classifications of remotely sensed data and of methods including remote sensing data in forest inventory, IIASA Interim Report. IIASA, Laxenburg, Austria.

Emanuel R.E., (2018), Climate change in the Lumbee River watershed and potential impacts on the Lumbee tribe of North Carolina, Journal of Contemporary Water Research \& Education, 163(1), 79-93.

Giardino C., Bresciani M., Villa P., Martinelli A., (2010), Application of remote sensing in water resource management: the case study of Lake Trasimeno, Italy, Water Resources Management, 24(14), 3885-3899.

Kaplan G., Avdan U., (2017), Object-based water body extraction model using Sentinel-2 satellite imagery, European Journal of Remote Sensing, 50(1), 137-143.

Kaplan G., Avdan Z.Y., Avdan U., Jovanovska T., (2019), Uzaktan algılama teknikleriyle uluslararası suların izlenmesı: Dojran Gölü örneği, International Disaster and Resilience Congress, Eskisehir, Turkey, ss. 413-418.

Kaya L.G., Yücedă̆ C., Duruşkan Ö., (2015), Burdur Gölü havzasının çevresel açıdan irdelenmesi, Mehmet Akif Ersoy Üniversitesi Fen Bilimleri Enstitüsü Dergisi, 6(1), 6-10. 
Kwang C., Jnr E.M.O., Amoah A.S., (2018), Comparing of landsat 8 and sentinel $2 A$ using water extraction indexes over Volta River, Journal of Geography and Geology, 10(1), 1-7.

Sarp G., Ozcelik M., (2017), Water body extraction and change detection using time series: A case study of Lake Burdur, Turkey, Journal of Taibah University for Science, 11(3), 381-391.

Temiz F, Durduran S.S., (2016), Monitoring coastline change using remote sensing and GIS technology: a case study of Actgöl Lake, Turkey, IOP Conference Series: Earth and Environmental Science, 44(4), 042033, doi:10.1088/1755-1315/44/4/042033.

URL-1, (2020), Landsat 7, Vikipedi Özgür Ansiklopedi, https://tr.wikipedia.org/wiki/Landsat_7, [Erişim 01 Mayıs 2020].

URL-2, (2020), Comparison of Landsat 7 and 8 bands with Sentinel-2, https://www.usgs.gov/media/images/comparison-landsat-7and-8-bands-sentinel-2, [Erişim 01 Mayıs 2020].

URL-3, (2020), Sentinel online, The European Space Agency, https://sentinel.esa.int/web/sentinel/home, [Erişim 01 Mayıs 2020].

URL-4, (2020), U.S. Geological Survey, https://www.usgs.gov/, Erișim 01 Mayıs 2020].

URL-5, (2020), Pan keskinleştirme, https://www.gezgin.gov.tr/pansharp/, [Erişim 10 Ağustos 2020].

Yang X., Zhao S., Qin X., Zhao N., Liang L., (2017), Mapping of urban surface water bodies from Sentinel-2 MSI imagery at $10 \mathrm{~m}$ resolution via NDWI-based image sharpening, Remote Sensing, 9(6), 596, doi: 10.3390/rs9060596.

Yiğitbaşoğlu H., Uğur A., (2010), Burdur Gölü havzasında arazi kullanım özelliklerinden kaynaklanan çevre sorunları, Ankara Üniversitesi Çevrebilimleri Dergisi, 2(2), 129-143. 